\title{
Henri Murger, Scènes de la vie de bohème
}

\section{Lise Sabourin}

\section{(2) OpenEdition}

\section{Journals}

\section{Édition électronique}

URL : http://journals.openedition.org/studifrancesi/2223

DOI : 10.4000/studifrancesi.2223

ISSN : 2427-5856

\section{Éditeur}

Rosenberg \& Sellier

\section{Édition imprimée}

Date de publication : 1 avril 2014

Pagination : 172

ISSN : 0039-2944

\section{Référence électronique}

Lise Sabourin, «Henri Murger, Scènes de la vie de bohème », Studi Francesi [En ligne], 172 (LVIII | I) |

2014, mis en ligne le 01 avril 2014, consulté le 18 septembre 2020. URL : http://

journals.openedition.org/studifrancesi/2223; DOI : https://doi.org/10.4000/studifrancesi.2223

Ce document a été généré automatiquement le 18 septembre 2020.

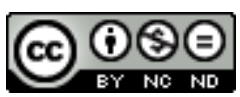

Studi Francesi è distribuita con Licenza Creative Commons Attribuzione - Non commerciale - Non opere derivate 4.0 Internazionale. 


\title{
Henri Murger, Scènes de la vie de bohème
}

\author{
Lise Sabourin
}

\section{RÉFÉRENCE}

HENRI MURGER, Scènes de la vie de bohème, présenté par Sandrine BERTHELOT, Paris, Flammarion, «GF», 2012, pp. 476.

1 Les Scènes de la vie de bohème, publiées en feuilletons au «Corsaire-Satan» ensuite devenu «Corsaire» de 1845 à 1849, ont été adaptées par Henri Murger, sur le conseil et avec la collaboration de Théodore Barrière, sous le titre La Vie de bohème, pièce jouée en 1849 avec un tel succès que des Variétés elle passa à la Comédie-Française, conférant à l'auteur une notoriété qui lui valut accès à la «Revue des deux mondes», légion d'honneur, retraite paisible de gentilhomme chasseur près de Fontainebleau, hommage $\mathrm{du}$ «Figaro» lors de funérailles quasi nationales et érection d'un monument par souscription au cimetière Montmartre.

Le recueil paru en volume en 1851 chez Michel Lévy, grâce à l'ajout d'une préface théorisante, d'un chapitre liminaire et de deux scènes d'épilogue, séduisit tellement le lectorat qu'il connut des rééditions successives jusqu'en 1890, ce qui n'a pourtant pas empêché l'œuvre de tomber dans un oubli certain jusqu'aux éditions annotées par Marcel Crouzet en 1949 (Bordas, «Les grands maîtres»), puis par Loïc Chotard et Graham Robb en 1988 (Gallimard, «Folio»). Sandrine Berthelot nous en procure une nouvelle, avec une présentation de grande qualité (pp. 7-54), des notes tenant compte des antérieures tout en les enrichissant, une chronologie et une bibliographie.

Le texte suit la dernière édition du vivant de Murger, tout en fournissant en annexes (pp. 437-468) la nouvelle «Son Excellence Gustave Colline», écartée lors de la 2 édition de 1852 au profit de «La Toilette des Grâces», ainsi que les scènes 8 et 9 du premier acte de la pièce écrite avec Barrière pour juger par cet échantillon des mutations opérées. En effet, la version scénique a figé grâce à sa reprise en opéra par Puccini en 1896 le 
mythe littéraire de la vie d'artiste tel que l'a forgé ce livre. Non pas que Murger l'ait inventé, car la génération romantique avait déjà vécu cette fraternité créatrice évoquée par Balzac dans Illusions perdues à travers «le Cénacle des grands hommes» conduit par d'Arthez ou par l'Histoire de la bohème commandée à Nerval en 1852. Mais, avec une nostalgie déjà parodique des Frédéric et Bernerette ou Mimi Pinson de Musset, Murger a mué en une bohème «catin» des années 1840 celle, plus «idéale», de 1830-35: peintres, sculpteurs et journalistes en mal de littérature de son temps ne sont plus de jeunes ambitieux pauvres mais issus de classes aisées et imprégnés de culture classique; ils sont devenus de précaires marginaux, autodidactes, vivotant de la petite presse, que réussite ou échec permettra seulement de répartir en vrais artistes ou en filous assassins.

4 Murger pratique la mise en scène de soi en Rodolphe, tout en fournissant des portraits contemporains dans ce qui s'avère un roman à clés du milieu artistique, au point qu'Alexandre Schanne s'est identifié en publiant ses Souvenirs de Schaunard en 1886, après que Champfleury et les Goncourts eurent publié respectivement leurs Aventures de Mlle Mariette (1853) et leurs Hommes de lettres (1860) qui nommaient sans détours, sur un ton au vitriol, les originaux de Musette et des rapins partageant sa vie de bohème. Murger était plus sentimental, plus idéaliste, malgré son rire salvateur de toute mélancolie excessive: Champfleury son ami n'hésita pas, dans ses Souvenirs et portraits de jeunesse (Dentu, 1872), à qualifier de «récits de mansarde», familièrement pittoresques, ce que lui-même montrait réalité plus cynique, tandis que Nadar, Lilioux et Noël protestaient de leur sérieux labeur par leur Histoire de Mürger, pour servir à l'histoire de la vraie bohème par trois Buveurs d'eau (Hetzel, 1862).

5 Certes, comme le dit Sandrine Berthelot, Murger a su «transfigurer le réel sordide en épopée plaisante de la médiocrité» (p. 40) grâce à son style de «nouvelles à la main». Ces récits courts et légers usent de l'ironie, cachent sous les effets de surprise, les bons mots, les traits spirituels d'une imagination prolixe et burlesque, la dure vie d'hôpital que risquent ces apprentis écrivains, comme il l'a lui-même subie. Entre rire et larmes, le nouvelliste a eu le don de brosser un portrait nuancé de la bohème, rassurant le lectorat bourgeois en lui présentant l'artiste comme un révolté temporaire, jouisseur potache que le temps assagira pour le faire rentrer dans le rang des commerçants ou des notaires après quelques années de joyeuse bouffonnerie de groupe, divertissante pour qui n'a pas vécu jeunesse aussi libérée: c'est ce qui fait de ce livre apparemment secondaire une œuvre majeure pour comprendre la société moderne où la nécessité tragique se mue en hasard des rencontres, où le créateur voit la réussite de son œuvre dépendre du pouvoir médiatique et commercial. 